\title{
Design and Implementation of Interleaved Boost Converter
}

\author{
K. Latha Shenoy ${ }^{\# ! 1}$, C.Gurudas Nayak ${ }^{* 2}$, Rajashekar P Mandi ${ }^{! 3}$ \\ \# Department of E\&E Engineering, NMAM Institute of Technology, Nitte, Karnataka, India \\ ${ }^{*}$ Dept of Instrumentation \& Control Engineering, MIT, MU, Manipal, Karnataka, India \\ 'School of Electrical Engineering, REVA University, Bangalore, India \\ ${ }^{1}$ lathashenoy@nitte.edu.in \\ 2 cg.nayak@manipal.edu(corresponding author) \\ ${ }^{3}$ rajashekarpm@reva.edu.in
}

\begin{abstract}
This paper deals with the design and simulation of interleaved boost converter for sustainable nonconventional energy sources. Both low and high power application demands the use of DC/DC converter. Two Phase Interleaved DC-DC Boost converters have many advantages compared to conventional boost converter such as very less current ripple, high efficiency, faster dynamics. Two phase interleaved converter is used to boost the output voltage to $400 \mathrm{~V}$ with higher efficiency of around $98 \%$. Further using interleaving device stress can be lowered and result in increase in efficiency. The proposed work is simulated using matlab simpowersystem.
\end{abstract}

Keyword- IBC, state space analysis, boost converter

\section{INTRODUCTION}

The increased environmental pollution have lead to the replacement of conventional sources by renewable sources like photovoltaic sources, windmills etc which result in turn an increase in the demand of DC- DC converters. Basically DC-DC converters are used to boost the input voltage to required output voltage and to get the high voltage gain [1]. The converter should be operated with the duty cycle of more than $50 \%$ to get higher gain in voltage level. The drawback of conventional boost converter is low voltage gain. Hence to overcome this problem an interleaved boost converter is proposed for renewable systems. As power densities continue to rise, interleaved boost designs become a powerful tool to manage input currents with increased efficiency. Two phase interleaved DC-DC boost converters are used for the application requiring demands such as low current ripple, high efficiency, faster dynamics, and higher power density. With the help of interleaving technique, the inductor current of interleaved boost converter can be reduced [2].In case of simple conventional boost converter current injected to the load is discontinuous and capacitor current has high ripple at the output. This is especially so in the emerging application areas of automotive power conversion, where the input voltage is low and large voltage boost are desired [3].

\section{TWO PHASE INTERLEAVED BOOST CONVERTER}

The schematic diagram of two phase interleaved boost converter is as shown in Fig1. It contains inductor L1 in parallel with inductor L2, switch Q1 in parallel with another switch Q2, diode D1 in parallel with diode D2, thereby forming two parallel channels between input and output circuits. All identical components are used for the circuit to obtain interleaving operation. Two switches are provided the gate signal which is out of phase by $180^{\circ}$.

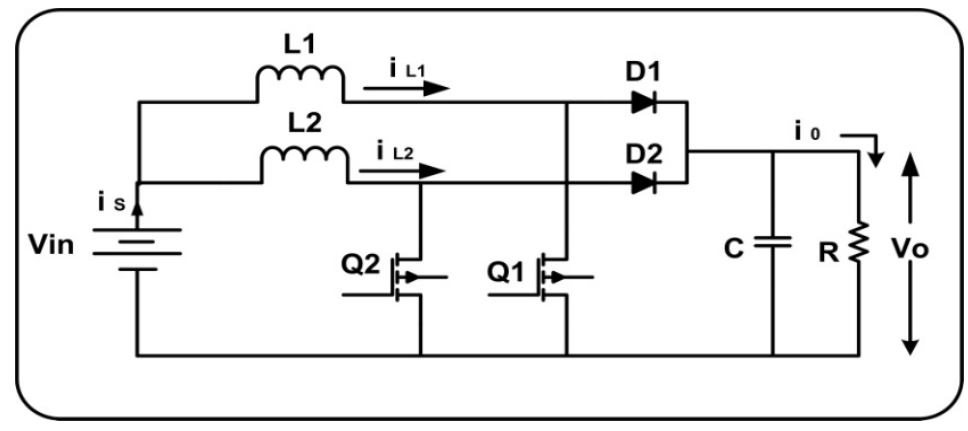

Fig 1: Schematic diagram of Interleaved Boost Circuit

Considering peak inductor ripple current as $20 \%$ of the average inductor current, the inductor value is obtained using the expression A. $D_{\max }$ is maximum value of duty cycle which 0.75 and $V_{\min }$ is the minimum of input voltage (100V). 


$$
L_{\text {phase }}=\frac{V_{\text {in }} D}{f_{s} \Delta i_{L}}
$$

By taking 2\% peak to peak capacitor ripple, capacitor value is obtained using given expression in B.

$$
\Delta V_{\text {out }}=\frac{V_{\text {in }} D}{T_{s} C_{\text {out }} R}
$$

This technique results in doubling of ripple frequency and resulting in reduction in ripple in the output voltage.

\section{MODES OF OPERATION}

The state space averaging technique is used for the analysis of interleaved boost converter. Using these equations mathematical model is obtained for the two phase interleaved boost converter. The operation of the converter is explained with the help of four switching modes of the converter. This converter comprises of four modes of operation. The state equations are derived as follows.

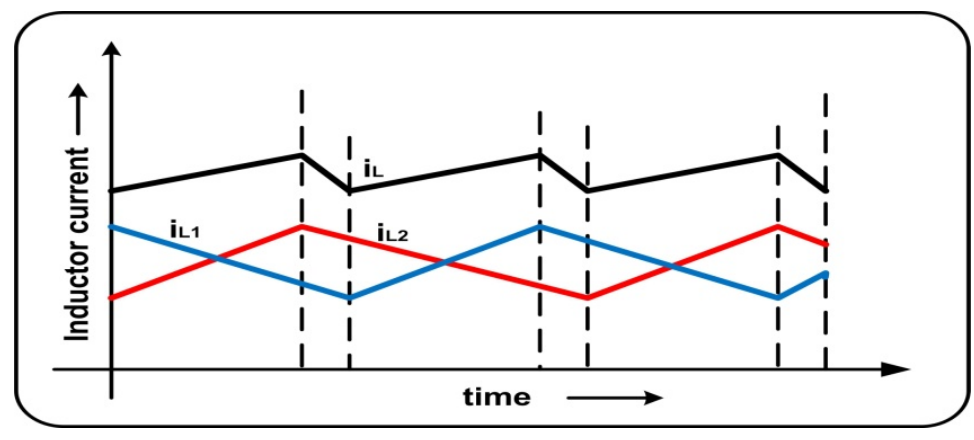

Fig 2: Ideal waveform for the interleaved converter

Mode-1: During mode 1 the switches Q1 and Q2 are switched on and the diodes D1and D2 are under off condition. Figure:1 shows the equivalent circuit for this mode.

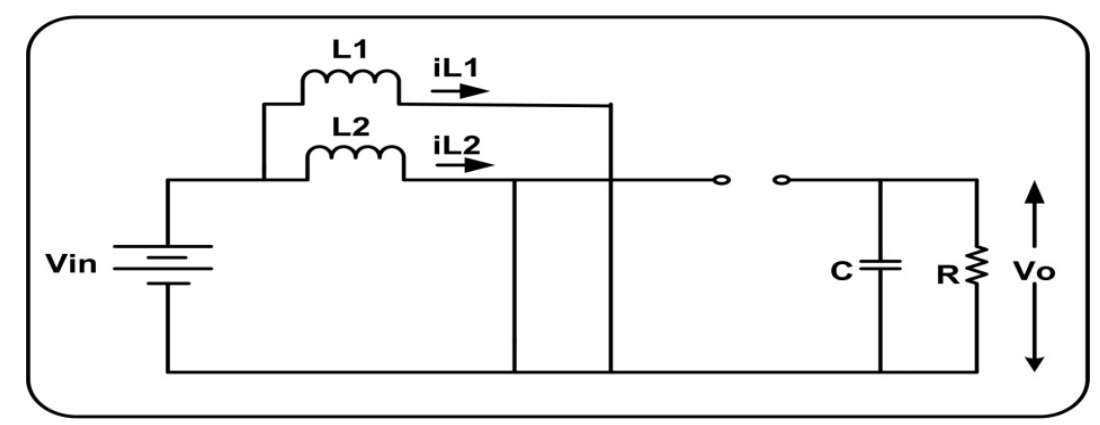

Fig 3: Equivalent circuit during mode 1

The following equations describes the mode 1 operation where inductor current $i_{L 1}$ and $i_{L 1}$ are taken as state variables . Also capacitor voltage Vo is considered as third state variable.

$$
\begin{gathered}
\frac{d i_{L 1}}{d t}=\frac{V_{s}}{L_{1}} \\
\frac{d v_{0}}{d t}=\frac{V_{0}}{R C} \\
\frac{d i_{L 2}}{d t}=\frac{V_{s}}{L_{2}}
\end{gathered}
$$




$$
A_{1}=\left[\begin{array}{ccc}
0 & 0 & 0 \\
0 & 0 & 0 \\
0 & 0 & \frac{-1}{R C}
\end{array}\right] \text { and } B_{1}=\left[\begin{array}{c}
\frac{1}{L_{1}} \\
\frac{1}{L_{2}} \\
V_{0}
\end{array}\right]
$$

During mode 2, the switch Q1 is in on condition and switch Q2 is in off condition and D1 is in off condition and D2 is in on condition respectively. The figure 4 represents the operation under mode 2.

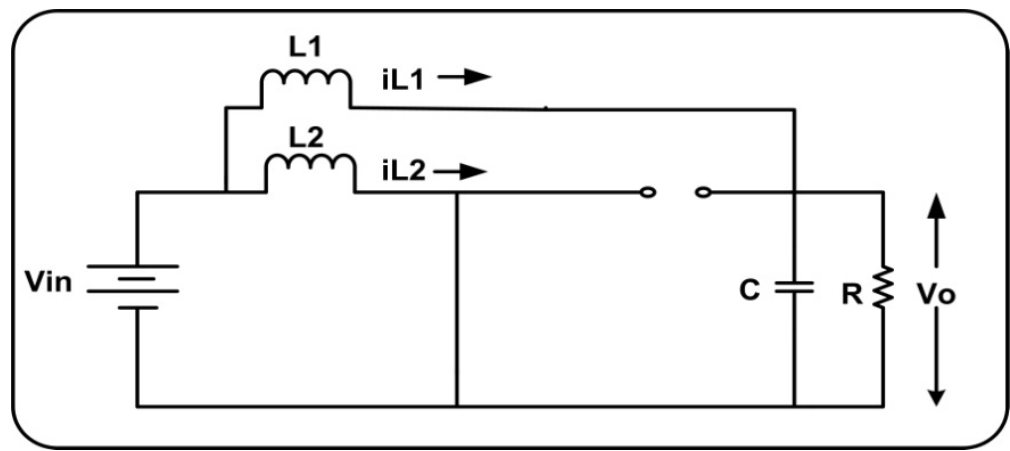

Fig:4 Equivalent circuit during mode 2

$$
\begin{gathered}
\frac{d i_{L 1}}{d t}=\frac{V_{s}}{L_{1}} \\
\frac{d i_{L 2}}{d t}=\frac{V_{s}}{L_{2}}-\frac{V_{0}}{L_{2}} \\
\frac{d v_{0}}{d t}=\frac{i_{L 2}}{C}-\frac{V_{0}}{R C} \\
A_{2}=\left[\begin{array}{ccc}
0 & 0 & \frac{1}{L_{1}} \\
0 & 0 & 0 \\
0 & \frac{1}{C} & \frac{-1}{R C}
\end{array}\right] \text { and } B_{2}=\left[\begin{array}{c}
\frac{1}{L_{1}} \\
\frac{1}{L_{2}} \\
0
\end{array}\right]
\end{gathered}
$$

In mode 3, the switch Q1 is in off condition and the switch Q2 is in on condition and the corresponding diodes such as D1 and D2 are in on and off conditions respectively. The figure:5 represents the operation of IBC under mode 3.

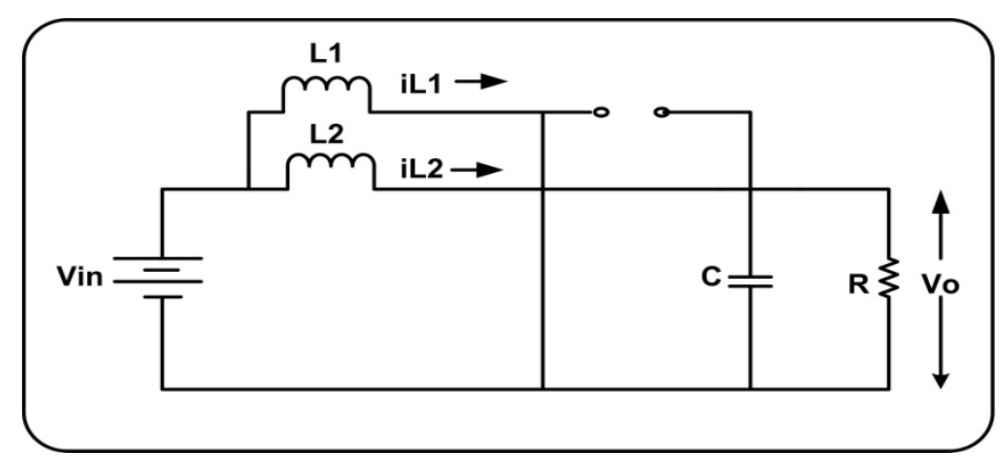

Fig 5 Equivalent circuit during mode 3 


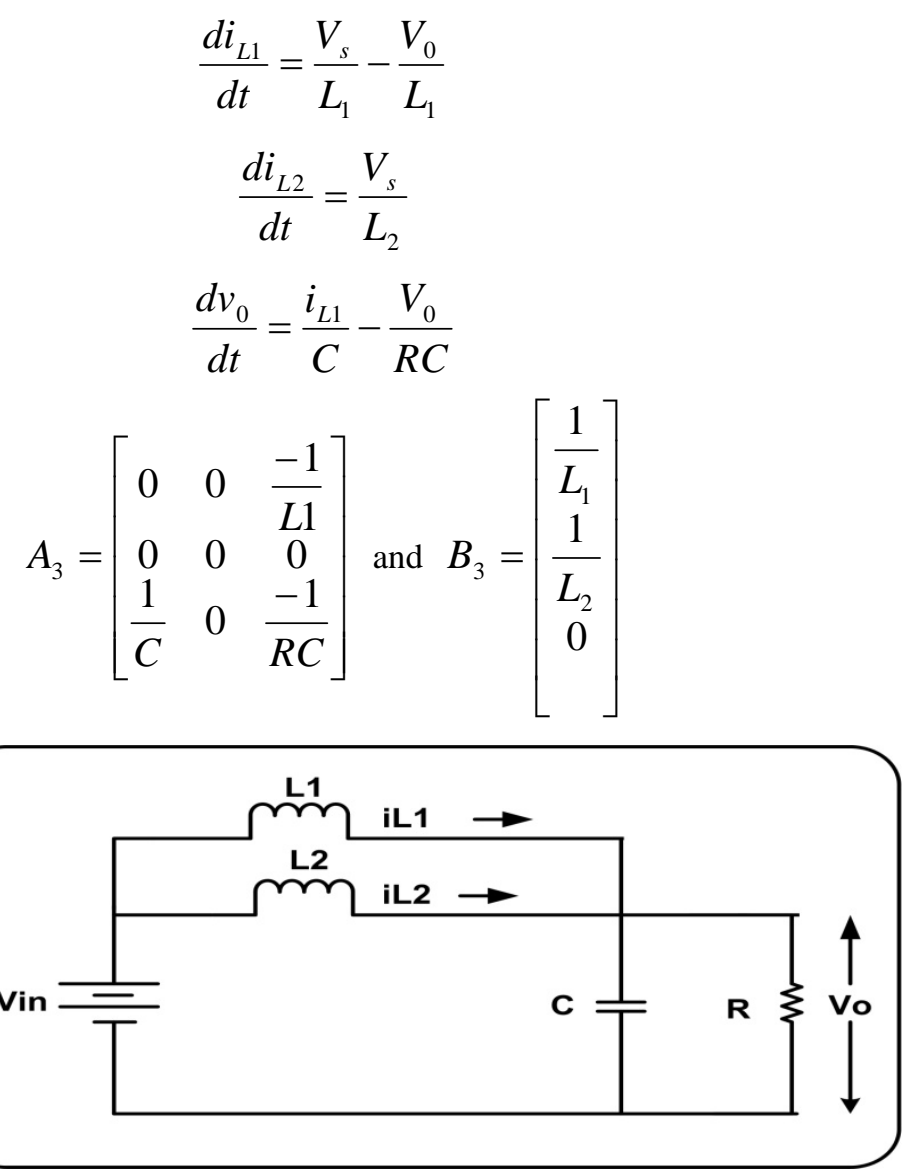

Fig 6: Equivalent circuit during mode 4

$$
\begin{gathered}
\frac{d i_{L 1}}{d t}=\frac{V_{s}}{L_{1}}-\frac{V_{0}}{L_{1}} \\
\frac{d i_{L 2}}{d t}=\frac{V_{s}}{L_{2}}-\frac{V_{0}}{L_{2}} \\
\frac{d v_{0}}{d t}=\frac{i_{L 1}}{C}+\frac{i_{L 2}}{C}-\frac{V_{0}}{R C} \\
A_{4}=\left[\begin{array}{ccc}
0 & 0 & \frac{1}{L_{1}} \\
0 & 0 & \frac{1}{L_{2}} \\
0 & \frac{1}{C} & \frac{-1}{R C}
\end{array}\right] \text { and } B_{4}=\left[\begin{array}{c}
\frac{1}{L_{1}} \\
\frac{1}{L_{2}} \\
0
\end{array}\right]
\end{gathered}
$$

The state equations and the coefficient matrix for the interleaved converter is given below.

$$
\begin{gathered}
X^{\bullet}=A X+B U \\
\mathrm{Y}=\mathrm{CX}+\mathrm{DU} \\
{[A]=A_{1} d_{1}+A_{2} d_{2}+A_{3} d_{3}+A_{4} d_{4}} \\
{[B]=B_{1} d_{1}+B_{2} d_{2}+B_{3} d_{3}+B_{4} d_{4}} \\
D=d_{1}+d_{2}+d_{3}+d_{4}
\end{gathered}
$$


The tranfer function of the boost converter are given as below.

$$
\begin{aligned}
& \frac{V_{o(s)}}{V_{i n(s)}}=\frac{1+s R C}{(1-D)\left[1+s \frac{L}{R(1-D)^{2}}+s^{2} \frac{L C}{(1-D)^{2}}\right]} \\
& \frac{V_{i n(s)}}{d_{(s)}}=\frac{1+s R C}{(1-D)^{2}\left[1+s \frac{L}{R(1-D)^{2}}+s^{2} \frac{L C}{(1-D)^{2}}\right]}
\end{aligned}
$$

TABLE 1: Design values of Interleaved Boost Circuit

\begin{tabular}{|c|l|c|}
\hline Sl.No & Description & Design parameter values \\
\hline 1 & Input voltage range & $100-200 \mathrm{~V}$ \\
\hline 2 & Output voltage & $400 \mathrm{~V}$ \\
\hline 3 & Output power & $5.0 \mathrm{KW}$ \\
\hline 4 & Load current & $25 \mathrm{~A}$ \\
\hline 5 & Switching frequency & $20 \mathrm{KHz}$ \\
\hline 6 & Inductance L1, L2 & $757 \mu \mathrm{H}$ \\
\hline 7 & Capacitance & $1171 \mu \mathrm{F}$ \\
\hline 8 & Load Resistance & 32 \\
\hline
\end{tabular}

\section{IV.RESULT \& DISCUSSION}

The interleaved boost converter is designed for switching frequency of $20 \mathrm{KHz}$. Switching pulse obtained have 180 degree phase shift for interleaving operation. The input voltage range taken is $100-200 \mathrm{~V}$. The nominal voltage of $100 \mathrm{~V}$ is taken as input to the converter. The waveforms for output voltage, input current, output current and output power is shown in the figures given below. The load resistance of 32 ohm is selected to which power of $5 \mathrm{KW}$ is given. Duty cycle of 0.75 is taken for the switching MOSFET. The state space analysis is done for open loop operation of interleaved boost converter.

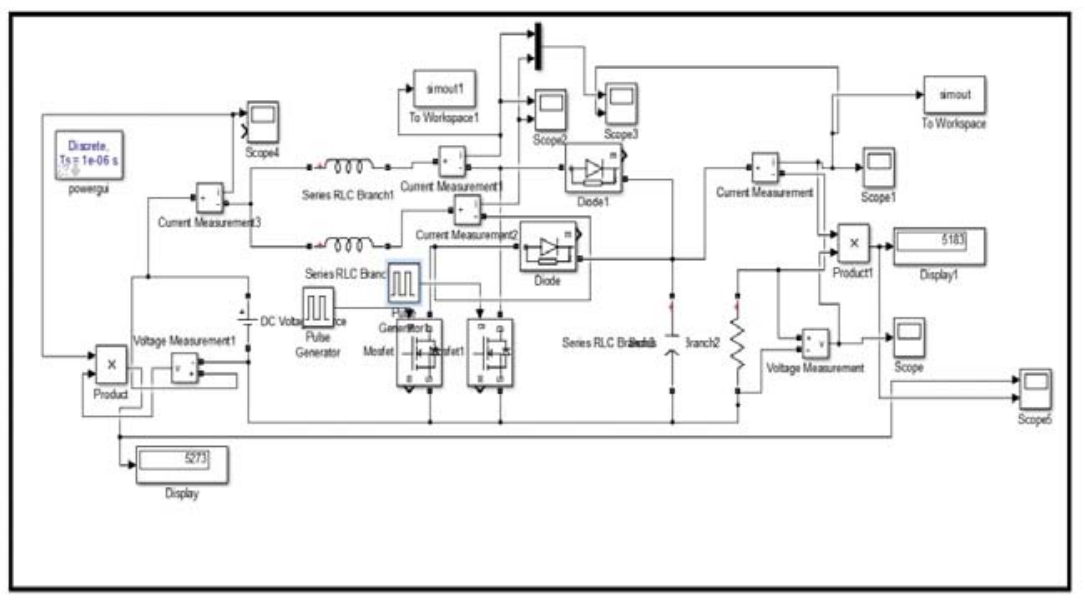

Fig 7: Simulation of interleaved Boost Converter

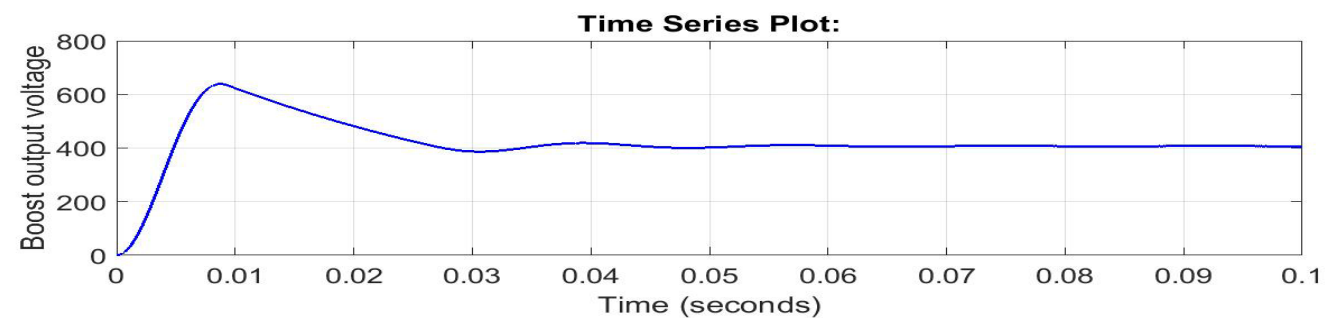

Fig 8 :Boost output voltage through load 


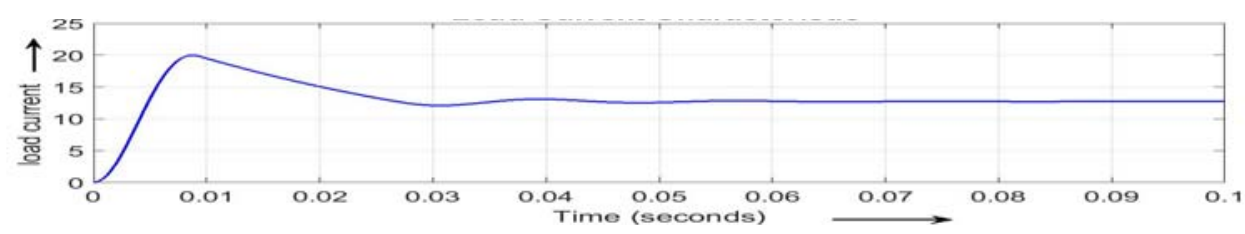

Fig 9 Output current through load

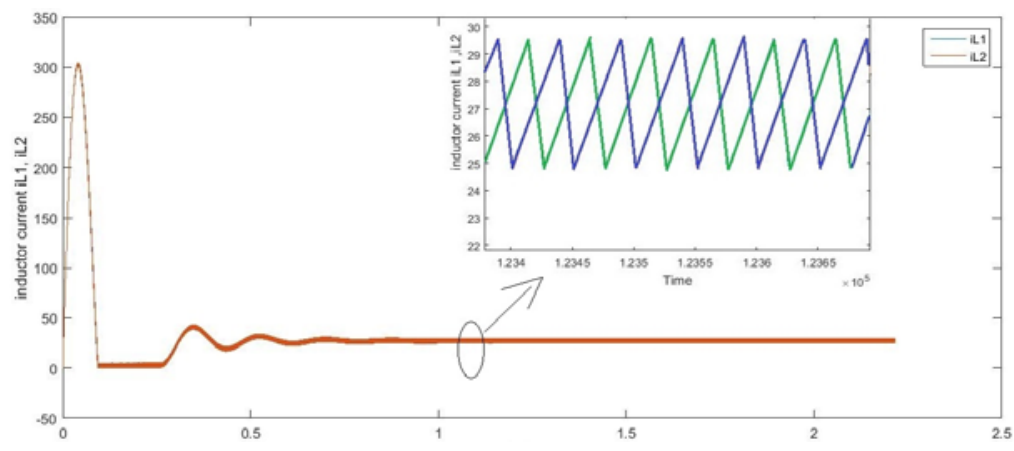

Fig 10 :. inductor current through L1, L2

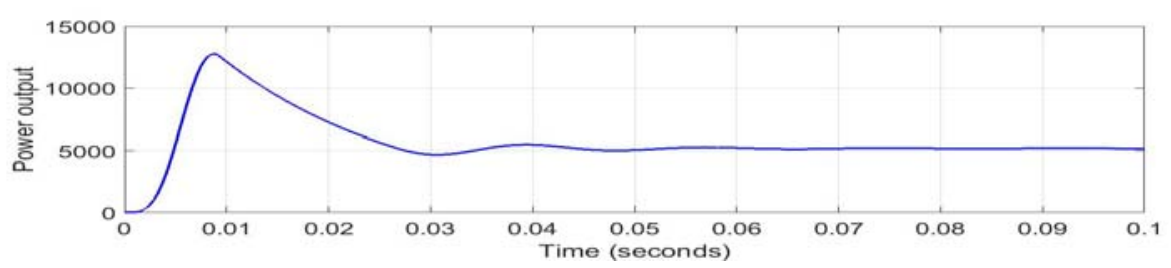

Fig: 11 Output power delivered to load

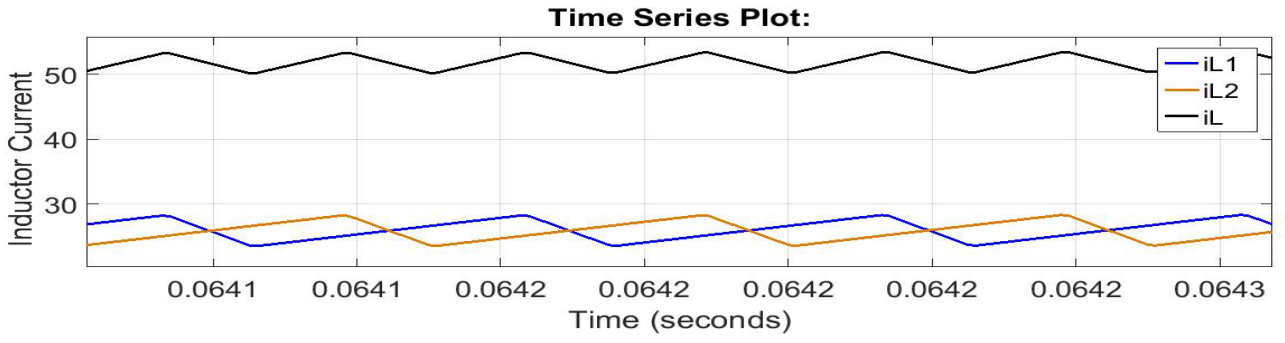

Fig 12: . Current through inductor L1, L2

\section{CONCLUSION}

Design and analysis of interleaved boost converter for renewable application is done in this paper. The input voltage of $100 \mathrm{~V}$ is boosted to output voltage of $400 \mathrm{~V}$ using interleaving technique. The operation is performed under open loop condition. The system is able to deliver the power to the load with higher efficiency. The efficiency of $98 \%$ is obtained using this technique. The evaluation by using mathematical model has been analyzed. The IBC has more advantages like high efficiency, low ripple etc. when compared to the conventional boost converters. This IBC can be applied to the grid connected system with the inverter circuit for converting DC to AC . The proposed interleaved boost converter is also suitable for the applications such as high-efficiency converters, a power-factor-correction circuit, and battery chargers.

\section{ACKNOWLEDGMENT}

Authors are very grateful to management of NMAM Institute of Technology Nitte, Udupi and REVA University, Bengaluru for providing resources to conduct this research work.

\section{REFERENCES}

[1] H. M. Swamy, K. P. Guruswamy, and S. P. Singh, “Design, Modeling and Analysis of Two Level Interleaved Boost Converter,” IEEE International Conference on Machine Intelligence and Research Advancement (ICMIRA), pp. 509-514, December, 2013

[2] A. Ghosh, S. Banerjee, M. K. Sarkar, and P. Dutta, "Design and Implementation of Type-II and Type-III Controller for DC-DC Switched-Mode Boost Converter by using K-Factor Approach and Optimization Techniques,” IET Power Electronics, vol. 9, no. 5, pp. 938-950, 2016. (doi: 10.1049/iet-pel.2015.0144)

[3] H. B. Shin, J. G. Park, S. K. Chung, H. W. Lee, T. A. Lipo , Generalised Steady-State Analysis of Multiphase Interleaved Boost Converter With Coupled Inductors. IEE Proc. Electr. Power Appl, Vol.152, No.3, Page 584-594,2005

[4] P. Li and B. Lehman, "A design method for paralleling current mode controlled DC-DC converters," IEEE Trans. on Power Electron., vol. 19, no.3Мay,2004. 
[5] I. Cadirci, A. Yafavi and M. Ermis, "Unity power factor boost converter with phase shifted parallel IGBT operation for medium power applications.” IEE. Proc.-Electr. Power Appl. Vol.149, No. 3, May 2002.

[6] D. Maksimovic, R. Zane, and R. Erickson, "Impact of Digital Control in Power Electronics.” IEEE International Symposium on Power Semiconductor Devices \&Ics Kitakyushu, Japan, May 2004.

[7] A. Newton, T. C. Green, and D. Andrew, AC/DC Power Factor Correction Using Interleaving Boost and Cuk Converters. IEEPower Electronics \& Variable Speed, Conference Publication, No.475, Page 293-298, 2000.

[8] B. A. Miwa, D. M. Otten, and M. F. Schlecht, High Efficiency Power Factor Correction Using Interleaving Techniques. IEEE Applied Power Electronics Conference and Exposition, Page.557-568, 1992.

[9] M. Chen, J. Sun, Reduced-Order Averaged Modeling of Active-Clam Coonverters. IEEE Transactions on Power Electronics, Volume 21, No.2, Page 487-494, 2006.

[10] H.Riazmontazer, J.S.Moghani, M.Taheri, H.Bayat, Averaged Modeling Of A New Bi-directional DC-DC Converter. IEEE 2nd Power Electronics, Drive System and Technologies Conference, page 574-579, 2011.

[11] Wai R. J., Lin C. Y., Duan R. Y. and Chang Y. R. (2007) "High-efficiency DC-DC converter with high voltage gain and reduced switch stress” IEEE Trans. Ind. Electron., vol. 54, no. 1, pp. 354-364. 15.

[12] Wu T. F., Lai Y. S., Hung J. C. and Chen Y. M. (2008) "Boost converter with coupled inductors and buck-boost type of active clamp" IEEE Trans. Ind. Electron., vol. 55, no. 1, pp. 154-162.

\section{AUTHOR PROFILE}
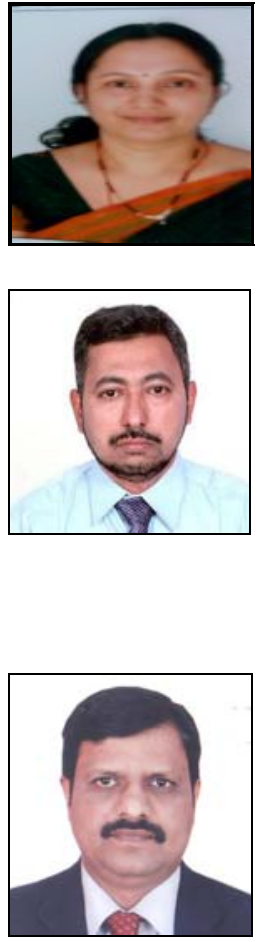

K.Latha Shenoy is presently working as assistant professor, department of Electrical \& Electronics engineering, NMAM Institute of Technology, Nitte. She has 13 years of teaching experience and 4 years of industrial experience. She received M.Tech degree in digital Electronics and Advanced communication from Manipal Institue of Technology, Manipal. Her research interests includes renewable energy systems, power electronics, control systems.

Dr.C. Gurudas Nayak, received his B.E. in Instrumentation Technology in 1988 from Gulbarga University, Gulbarga India and M.S. in Communication Engineering in the year 1996 from NewPort University, USA and PhD from Manipal University, Manipal, India in the year 2008. He has 28 years of Industrial /teaching experiences and published 76 papers in International, National Conferences and journals. He is currently working as a Professor in the Instrumentation and Control Engineering department, Manipal Institute of Technology,Manipal University, Manipal. His research interests include Communication Networks, Instrumentation and Transducers and Mobile Telephone Systems.

Dr. Rajashekar P. Mandi is presently working as Director of School of Electrical Engineering, REVA University, Bangalore. Before joining REVA University, he worked in Central Power Research Institute, Bangalore for more than 26 years in research. He received M. Tech. degree in Energy Systems Engineering from Visweswaraiah Technological University, Belgaum with $3^{\text {rd }}$ rank and Ph.D in Power and Energy from NITK, Surathkal through research. He is a professional member of IEEE. He is accredited energy auditor from Bureau of Energy Efficiency (BEE), Govt. of India. He is presently chairman of Society for Energy Efficiency \& Manager (SEEM) Karnataka Chapter 